\title{
KIDNEY FAILURE SCREENING IN THE GENERAL POPULATION OF RURAL AFRICA
}

\author{
BAH Alpha Oumar ${ }^{1}$, BALDE Mamadou Cellou ${ }^{2}$, KIMSO Oumou ${ }^{1}$, KABA Mohamed Lamine ${ }^{1}$, NGAMMIE \\ Christelle Raïssa ${ }^{1}$
}

${ }^{1}$ Department of Nephrology, Dialysis, Donka National Hospital, BP 234, Conakry, Republic of Guinea.

${ }^{2}$ Department of Nephrology, Dialysis CHIVA, BP01 09017, Foix Cedex, France.

\section{SUMMARY}

Kidney failure is a silently progressive disease too often unknown to the patients. The objective of this study was to assess the impact of kidney disease in Conakry so as to develop strategies for early detection and prevention.

This was a descriptive-type prospective study carried out over six months, from January 31 to July 31, 2012. The study was carried out in two areas: In health facilities where the population were at a higher risk of developing kidney disease (diabetes, uropathies, infectious diseases and HIV, hypertension and cardiovascular disease), and in an apparently healthy population.

In the study we included black subjects hospitalised in different targeted wards, as well as fully active apparently healthy subjects of the general population.

Renal function was assessed with the simplified MDRD formula.

Data collection included clinical parameters: Blood pressure, weight, height and blood laboratory parameters (creatinine, glucose) and urine (urine dipstick, 24h quantitative proteinuria).

One hundred and ninety-nine patients were selected for the study: 117 men and 82 women ageing from 20 to 90 years. The prevalence of renal failure was $59 \%$ in the population at risk, with $53.3 \%$ of men and $16 \%$ in apparently healthy population with $60 \%$ of men with a statistically significant difference: $p=0.00000001$. Proteinuria was observed in 86 patients in the population at risk against 19 in the healthy population.

\section{KEYWORDS}

Conakry, screening, kidney disease, African population.

\section{INTRODUCTION}

Chronic kidney disease is a major public health problem. Its true incidence is unknown in Africa, but it is linked to an increase in certain chronic diseases that may be responsible for renal failure. Among these diseases, diabetes and hypertension are predominant and account for 50$60 \%$ of end-stage renal disease (ESRD) [1]. Urological diseases, cardiovascular diseases, HIV infection, and nephrotoxic drugs are also responsible for this condition. As recommended by K/DOQI, early detection of chronic kidney disease (CKD) can be achieved simply through the evaluation of serum creatinine and/or albuminuria [2].

Kidney failure is a silently progressive disease too often unknown by patients - clinical signs appear late, once

ADDRESS FOR CORRESPONDENCE: BAH Alpha Oumar, Nephrology Service, Donka National Hospital, BP 234, Conakry, Republic of Guinea., Email: bahalphaoumar1@gmail.com 
renal function is already impaired. Therefore, the high incidence of renal failure in our hospital activities $(60 \%$ of hospitalisations in Nephrology, of which $65 \%$ are endstage renal disease), as well as difficulties in their care (11 hemodialysis stations for 11-million inhabitants) have motivated us to do a study on screening for kidney failure.

The objective was to determine the epidemiology of renal disease in Conakry in order to develop strategies for early detection and prevention thereby contributing to the reduction of morbidity and mortality of kidney disease.

\section{MATERIAL AND METHODS}

This study was conducted in the city of Conakry, the capital of the Republic of Guinea, at the Diabetes Services, Infectious Diseases, Cardiology and Urology, University Hospital, University Gamal Abdel Nasser and the People's Palace.

This was a descriptive-type prospective study of a sixmonth period from January 31 to July 31, 2012.

The study was conducted in two areas: In health facilities with a population with a classic risk of kidney disease, and in an apparently healthy population.

Criteria for inclusion were:

1. Black subjects.

2. Population at risk for chronic kidney disease: Patients in the different wards mentioned above.

3. Apparently healthy general population: Participation in the study was voluntary. Those who did not agree to participate in the study were not included.

Renal function was assessed with the simplified MDRD formula:

$186 \times(\text { serum creatinine })^{-1.154} \times$ age $^{-0.203} \times K(K=0.742$ for women and 1.21 for men).

Definition of variables:

1. Renal failure was defined as a creatinine clearance calculated by the MDRD formula below $90 \mathrm{ml} / \mathrm{min}$ (MDRD).

2. Population with classic risk factors were patients hospitalised in Diabetology, Infectious Diseases, Cardiology and Urology wards.

3. The apparently healthy general population were made up of students, civil servants, housewives, merchants, and fully active workers, with no medical history and with no alcohol and tobacco abuse, not on medication, and who had not consulted a health facility in the last three years.
Data collection included clinical parameters: Blood pressure, weight, height and blood laboratory parameters (creatinine, glucose) and urine (urine dipstick, quantitative proteinuria $24 \mathrm{~h})$.

Our results were presented in charts, Word, Excel 2007 and Epi-info version 3.5.1 were used for data processing and statistical analysis.

\section{ETHICS}

After obtaining permission to survey the patients from departmental heads, we saw each patient individually to explain the objectives of the study so as to obtain their verbal, free and informed consent. Patients with a clearance under $90 \mathrm{ml} / \mathrm{min}$ and abnormal dipstick were referred to the Nephrology Department. The confidentiality clause was observed.

\section{RESULTS}

One hundred and ninety-nine (199) patients were selected for the study, 117 men and 82 women, aged between 20 and 90 years. They were divided into two groups:

1. The population at risk for renal disease was 105 patients, 61 men and 44 women. The average age was $52.45 \pm 19.85$ years. The most affected age group was 61 to 70 years $(32 \%)$, followed by 51 to 60 years $(19 \%)$.

2. In the apparently healthy population we found 94 people (56 men and 38 women). The average age was $24.6 \pm 12.66$ years.

The prevalence of renal failure was $59 \%$ in the at-risk population $(53.3 \%$ men) and $16 \%$ in the apparently healthy population $(60 \%$ men) with a statistically significant difference: Chi $2=38.63 ; \mathrm{p}=0.00000001$; relative risk $=$ 3.71 .

Among the at-risk population, renal failure was observed in $65.21 \%$ of the cases of hypertension, in $57.89 \%$ of uropathies, in $50 \%$ of $\mathrm{HIV}$, in $50 \%$ of diabetes mellitus, in $100 \%$ of uropathies associated with hypertension, in $73.68 \%$ of diabetes associated with hypertension, and $50 \%$ of uropathies with HIV. Among them, out of 62 cases of renal insufficiency, we found that 25 had a creatinine clearance between 60 and $89 \mathrm{ml} / \mathrm{min}, 25$ had a creatinine clearance between 30 and $59 \mathrm{ml} / \mathrm{min}$, and it was between 15 and $29 \mathrm{ml} / \mathrm{min}$ for eight patients and $\leq 15 \mathrm{ml} / \mathrm{min}$ for four patients.

In the at-risk population, proteinuria was positive in 86 patients, hematuria in 42 patients, leucocyturia in 40 patients, nitrates in 15 patients and glycosuria in 31 patients.

In the apparently healthy population, renal failure was observed in 15 patients out of the 94. Among them, $12 \mathrm{had}$ 
a creatinine clearance between 60 and $89 \mathrm{ml} / \mathrm{min}$, two had a creatinine clearance between 30 and $59 \mathrm{ml} / \mathrm{min}$, and one had a creatinine clearance between 15 and $29 \mathrm{ml} / \mathrm{min}$.

In this apparently healthy population, 19 individuals were found with proteinuria, three with hematuria, six with leucocyturia, two with nitrates, and one with glycosuria.

\section{DISCUSSION}

This study, a first in the Republic of Guinea, established the prevalence of chronic kidney disease not only in subjects exposed to kidney disease, but in apparently healthy subjects with no risk factor for renal disease as well. These two populations were not matched by age and sex. The at-risk population was hospitalised in the departments where renal disease was common. The apparently healthy population was carefully selected - fully active subjects with no medical history, non-drinkers and non-smokers, not on medication and had not consulted a health facility in the last three years. We found that the incidence of renal failure was higher in the at-risk population than in the apparently healthy population with a statistically significant difference

$(\mathrm{p}=0.00000001)$. Although this difference in prevalence could be partly explained by the age difference, we can say that there is an association between exposure and disease onset. The traditional cardiovascular risk factors such as hypertension and diabetes mellitus become increasingly common in developing countries, and are often associated with chronic kidney disease [3, 4].

The prevalence of CKD was reported mainly in developed countries. In the United States of America, it has recently increased from 11\% between 1988 and 1994 [5], to 13\% between 1999 and 2004 [6]. The prevalence of this condition is reported to be $16 \%$ in Australia [7], 10.1\% in China [8], but $3.3 \%$ in Italy [9]. In developing countries, all available data on CKD come from in-hospital studies. In Kinshasa, a screening study in the general population of unknown CKD noted a prevalence of $33 \%$ [10].

In our study, the average age of patients in the atrisk population was two times higher than in the other population. This is explained by the fact that hospitalised patients had chronic diseases, while the "healthy" population was recruited from young fully active subjects (mean age $24.6 \pm 12.66$ years). These patients were particularly young subjects similar to the reported profiles in most studies done in developing countries [10]. Indeed, the average age of terminal chronic renal failure patients in Senegal and Burkina Faso was 46 years $[11,12]$. These youths provide the human resources needed for the economic development of developing nations.

We noted that in these two groups there was a male predominance; this was consistent with previous studies that have reported that the male gender is a risk factor for chronic kidney disease, probably because of hyperandrogenism [13].
In our series, a significant number of adults had proteinuria and CKD risk factors (hypertension, diabetes mellitus, uropathies, and HIV) and these factors were often associated. In Kinshasa, Sumaili noted a high prevalence of CKD and its risk factors [10]. An increase in the annual incidence of admissions for CKD was observed in Kinshasa according to Sumaili. This might actually reflect an outbreak of this disease in the general population, but could also be due to a better understanding of Nephrology Department by the population.

In our series, no renal biopsy was performed, but patients with abnormalities were referred in the Nephrology Department. We can say with a high presumption that glomerular disease (proteinuria and hematuria), urinary tract infection (pyuria and nitriuria), as well as hypertension and diabetes mellitus were the leading causes of kidney disease in our population. This observation is similar to that reported in Senegal [14].

\section{CONCLUSION}

Chronic kidney disease is a common condition whose clinically silent symptoms are responsible for the delay in diagnosis in developing countries. Risk factors for developing renal disease were hypertension, diabetes mellitus, uropathies and HIV. In an apparently healthy population, glomerular diseases and urinary tract infections were the leading cause of chronic kidney disease. Therefore, characterised by its latency and quiet character, only routine screening, or in high-risk groups, would allow early diagnosis and possibly adequate care.

This screening study could be feasible in a large part of our population, thereby enabling the establishment of a national registry for renal disease.

\section{REFERENCES}

1. Coresh J, Selvin E, Stevens LA, Prevalence of chronic kidney disease in the United States, Jama, 2007, 298:20382047.

2. K/DOQI, Clinical practice guidelines for chronic kidney disease: Evaluation, classification, and stratification, Am J Kidney Dis, 2002, 39:S1-266.

3. Krzesinski JM, Sumaili EK, Cohen EP, How to tackle the avalanche of chronic kidney disease in sub-Saharan Africa: the situation in the Democratic Republic of Congo as an example, Nephrol Dial Transplant, 2007, 22:332-335.

4. Amuna P, Zotor FB, Epidemiological and nutrition transition in developing countries: Impact on human health and development, Proc Nutr Soc, 2008, 67:82-90.

5. Coresh J, Astor BC, Greene T, Eknoyan G, Levey AS, Prevalence of chronic kidney disease and decreased kidney function in the adult US population: Third National 
Health and Nutrition Examination Survey, Am J Kidney Dis, 2003, 41:1-12.

6. Coresh J, Selvin E, Stevens LA, Manzi J, Kusek JW, Eggers P, Van Lente F, Levey AS, Prevalence of chronic kidney disease in the United States, JAMA, 2007, 298:2038-2047.

7. Chadban SJ, Briganti EM, Kerr PG, Dunstan DW, Welborn TA, Zimmet PZ, Atkins RC, Prevalence of kidney damage in Australian adults: The Aus Diab kidney study, I Am Soc Nephrol, 2003, 14:S131-138.

8. Zhang L, Zuo L, Xu G, Wang F, Wang M, Wang S, Lv J, Liu L, Wang H, Community-based screening for chronic kidney disease among populations older than 40 years in Beijing, Nephrol Dial Transplant, 2007, 22:10931099.

9. Cirillo M, Laurenzi M, Mancini M, Zanchetti A, Lombardi C, De Santo NG, Low glomerular filtration in the population: Prevalence, associated disorders, and awareness, Kidney Int, 2006, 70:800-806.

10. Sumaili EK, Krzesinski JM, Cohen EP, Nseka NM,
Épidémiologie de la maladie rénale chronique en République démocratique du Congo, une revue synthétique des études de Kinshasa, la capital, Néphrologie \& Thérapeutique, 2010, Volume 6, 4: 232-239.

11. Diouf B, Ka EF, Niang A, Diouf ML, Mbengue M, Diop TM, Etiologies of chronic renal insufficiency in an adult internal medicine service in Dakar, Dakar Med, 2000, 45:62-65.

12. Sakandé J, Sawadogo M, Nacoulma EW, Sidikath ES, Kabré E, Sawadogo S, Lengani A, Profil biologique de l'insuffisance rénale chronique, Ann Biol Clin Qué, 2006, 43:3-8.

13. Gould MM, Mohamed-Ali V, Goubet SA, Yudkin JS, Haines AP, Microalbuminuria associations with height and sex in non-diabetic subjects, BMJ, 1993, 306:240242.

14. Diouf B, Ka EF, Niang A, Diouf ML, Mbengue M, Diop TM, Etiologies of chronic renal insufficiency in an adult internal medicine service in Dakar, Dakar Med, 2000, 45:62-65.

TABLE I: OVERVIEW OF THE STUDY POPULATION

\begin{tabular}{|l|l|l|l|l|l|l|}
\hline \multirow{2}{*}{ Age } & Male & Female & Male & Female & \multirow{2}{*}{} & \multirow{2}{*}{} \\
\cline { 2 - 6 } & & & & & \multirow{2}{*}{ Total } & $\%$ \\
\hline $20-30$ & 4 & 11 & 35 & 26 & 76 & 38,19 \\
\hline $31-40$ & 6 & 6 & 11 & 9 & 32 & 16,08 \\
\hline $41-50$ & 10 & 4 & 4 & 1 & 19 & 9,54 \\
\hline $51-60$ & 8 & 8 & 2 & 1 & 19 & 9,54 \\
\hline $61-70$ & 15 & 12 & 4 & 1 & 32 & 16,08 \\
\hline $71-80$ & 13 & 3 & 0 & 0 & 16 & 8,04 \\
\hline $81-90$ & 5 & 0 & 0 & 0 & 5 & 2,53 \\
\hline Total & 61 & 44 & 56 & 38 & 199 & 100 \\
\hline
\end{tabular}

TABLE II: PREVALENCE OF KIDNEY DISEASE IN THE GENERAL POPULATION

\begin{tabular}{|l|l|l|l|}
\hline & At-risk population & Healthy population & Total \\
\hline Renal disease & $62(59 \%)$ & $15(16 \%)$ & 77 \\
\hline Normal renal function & $43(41 \%)$ & $79(84 \%)$ & 122 \\
\hline Total & 105 & 94 & 199 \\
\hline
\end{tabular}

$\mathrm{OR}=7.59 ; \mathrm{RR}=2.28 ; 95 \% \mathrm{CI}$

Chi2 Yates corrected $=37.03 ; \mathrm{p}=0.00000001$ 
TABLE III: DISTRIBUTION OF POPULATION WITH RENAL DISEASE BY GENDER

\begin{tabular}{|l|l|l|l|}
\hline & At-risk population & Healthy population & Total \\
\hline Male & $33(53,3 \%)$ & $9(60 \%)$ & $39(50,6 \%)$ \\
\hline Female & $29(46,7 \%)$ & $6(40 \%)$ & $38(49,4 \%)$ \\
\hline Total & 62 & 15 & 77 \\
\hline
\end{tabular}

TABLE IV: DISTRIBUTION OF PATIENTS WITH RISK FACTORS ACCORDING TO THE CREATININE CLEARANCE

\begin{tabular}{|l|l|l|l|l|l|l|l|l|}
\hline Clairance & Diabetes & HTA & VIH & Uro & Diab + HTA & HTA + Uro & VIH + Uro & Total \\
\hline $60-89$ & 2 & 6 & 3 & 5 & 8 & 2 & 1 & 27 \\
\hline $30-59$ & 3 & 7 & 8 & 3 & 2 & 0 & 0 & 23 \\
\hline $15-29$ & 1 & 2 & 1 & 2 & 2 & 0 & 0 & 8 \\
\hline$\leq 15$ & 1 & 0 & 0 & 1 & 2 & 0 & 0 & 4 \\
\hline Total & 7 & 15 & 12 & 11 & 14 & 2 & 1 & 62 \\
\hline
\end{tabular}

TABLE V: DISTRIBUTION OF THE APPARENTLY HEALTHY POPULATION WITH RENAL DISEASE

\begin{tabular}{|l|l|l|l|l|l|}
\hline Clairance $(\mathrm{ml} / \mathrm{mn})$ & & $60-89$ & $30-59$ & $29-15$ & $\leq 15$ \\
\hline Male & 7 & 2 & 0 & 0 \\
\hline Female & 5 & 0 & 1 & 0 \\
\hline TOTAL & 12 & 2 & 1 & 0 \\
\hline
\end{tabular}

TABLE VI: CHANGES IN URINARY PARAMETERS IN THE STUDY POPULATION (N = 199)

\begin{tabular}{|l|l|l|l|}
\hline Parameters & At-risk population & $\begin{array}{l}\text { Apparently healthy } \\
\text { population }\end{array}$ & Total \\
\hline Proteins & $86(82 \%)$ & $19(20 \%)$ & $105(53 \%)$ \\
\hline Blood & $42(30 \%)$ & $3(3 \%)$ & $45(22 \%)$ \\
\hline Glucose & $31(30 \%)$ & $1(1 \%)$ & $32(16 \%)$ \\
\hline Nitrites & $15(14 \%)$ & $2(2 \%)$ & $17(9 \%)$ \\
\hline Leucocytes & $40(38 \%)$ & $6(6 \%)$ & $46(23 \%)$ \\
\hline
\end{tabular}

